\title{
(2) OPEN ACCESS \\ Progression from ocular hypertension to visual field loss in the English hospital eye service
}

\author{
Stephen R Kelly (D), ${ }^{1}$ Anthony P Khawaja (D), ${ }^{2}$ Susan R Bryan (D), 1 \\ Augusto Azuara-Blanco (D) , John M Sparrow (D) , ${ }^{4,5}$ David P Crabb (i) ${ }^{1}$
}

\begin{abstract}
- Additional material is published online only. To view please visit the journal online (http://dx.doi.org/10.1136/ bjophthalmol-2019-315052).

${ }^{1}$ Division of Optometry and Visual Science, School of Health Sciences, City, University of London, London, UK ${ }^{2}$ NIHR Biomedical Research Centre for Ophthalmology, Moorfields Eye Hospital and University College London, London, UK

${ }^{3}$ Centre for Public Health, Queen's University Belfast, Belfast, UK

${ }^{4}$ Bristol Eye Hospital, Population Health Sciences, University of Bristol, Bristol, UK

${ }^{5}$ The Royal College of Ophthalmologists National Ophthalmology Database Audit, Royal College of Ophthalmologists, London, UK
\end{abstract}

\section{Correspondence to} Professor David P Crabb, Division of Optometry \& Visual Science, City, University of London, London EC1V OHB, UK; David.Crabb.1@city.ac.uk

Received 6 August 2019 Revised 3 December 2019 Accepted 19 December 2019

\section{Check for updates}

(C) Author(s) (or their employer(s)) 2020. Re-use permitted under CC BY-NC No commercial re-use. See rights and permissions. Published by BMJ.

To cite: Kelly SR, Khawaja $\mathrm{AP}$, Bryan SR, et al. Br J Ophthalmol

2020:104:1406-1411.

\section{ABSTRACT}

Background There are more than one million National Health Service visits in England and Wales each year for patients with glaucoma or ocular hypertension (OHT). With the ageing population and an increase in optometric testing, the economic burden of glaucoma-related visits is predicted to increase. We examined the conversion rates of $\mathrm{OHT}$ to primary open-angle glaucoma (POAG) in England and assessed factors associated with risk of conversion.

Methods Electronic medical records of 45309 patients from five regionally different glaucoma clinics in England were retrospectively examined. Conversion to POAG from OHT was defined by deterioration in visual field (two consecutive tests classified as stage 1 or worse as per the glaucoma staging system 2). Cox proportional hazards models were used to examine factors (age, sex, treatment status and baseline intraocular pressure (IOP)) associated with conversion.

Results The cumulative risk of conversion to POAG was $17.5 \%(95 \% \mathrm{Cl} 15.4 \%$ to $19.6 \%)$ at 5 years. Older age (HR 1.35 per decade, $95 \% \mathrm{Cl} 1.22$ to $1.50, \mathrm{p}<0.001$ ) was associated with a higher risk of conversion. IOP-lowering therapy (HR $0.45,95 \% \mathrm{Cl} 0.35$ to $0.57, \mathrm{p}<0.001$ ) was associated with a lower risk of conversion. Predicted 5-year conversion rates for treated and untreated groups were $14.0 \%$ and $26.9 \%$, respectively.

Conclusion Less than one-fifth of OHT patients managed in glaucoma clinics in the UK converted to POAG over a 5-year period, suggesting many patients may require less intensive follow-up. Our study provides real-world evidence for the efficacy of current management (including IOP-lowering treatment) at reducing risk of conversion.

\section{INTRODUCTION}

Referral guidelines for ocular hypertension (OHT) or other glaucoma-related conditions in England currently require a repeated applanation tonometry intraocular pressure (IOP) measurement of above $24 \mathrm{~mm} \mathrm{Hg}$ if referring on IOP alone. ${ }^{1}$ Previously guidelines set the IOP threshold for referral at 21 $\mathrm{mm} \mathrm{Hg}$ and the EPIC-Norfolk study reported a prevalence of $10 \%$ for OHT in the English county of Norfolk using this IOP cut-off. ${ }^{2}$ Current guidance recommends that IOP-lowering eye-drops may be offered to patients with high IOP if they are at risk of visual impairment in their lifetime. ${ }^{1}$ The reported rate of conversion from OHT to primary openangle glaucoma (POAG) is variable in the literature with, for example, a 5 -year conversion rate of anywhere between $4.4 \%$ and $25 \% .^{3-6}$ Robust data on the likelihood of developing glaucoma for those with OHT are required to inform monitoring guidelines in terms of cost-effectiveness and acceptability to patients, eye care providers and commissioners of National Health Service (NHS) services.

Primary care general practitioners do not generally have the appropriate training or equipment for monitoring patients with OHT. Standard UK practice as such is to monitor in secondary care in hospital eye services (HESs). This monitoring places a strain both on eye care services and patients, as monitoring in specialist eye clinics can be inconvenient, may lead to 'overtreatment' and is expensive for the NHS. ${ }^{2}$ As up to half of POAG is characterised as normal tension glaucoma in Europeans, high IOP is neither a necessary nor a sufficient condition of glaucoma. ${ }^{27}$ Therefore, it is likely that a proportion of patients with OHT are receiving unnecessarily intensive follow-up or treatment. With an ageing population and an increase in optometric testing, the number of patients being seen in clinics with glaucoma-related conditions is expected to rise, placing further strain on these services. ${ }^{8}$ Currently, there are significant glaucoma clinic appointment backlog issues in many ophthalmology departments in England and Wales. ${ }^{10} 11$

HESs in the UK are transitioning to electronic medical record (EMR) systems to store structured patient data digitally, although progress is slow. ${ }^{12} 13$ Glaucoma clinics, in particular, have the ability to store structured data relevant to OHT patients such as IOP readings, visual field (VF) test results and which medications (if any) they are taking. The aims of this study were to use EMR data from five glaucoma clinics in England to retrospectively analyse what happens to OHT patients. The primary aim was to estimate the proportion of OHT cases that converted to POAG within 5 years and to examine factors associated with this conversion. Our secondary objective was to consider the burden (number of unique scheduled appointments) that OHT patients place on glaucoma clinics, relative to other conditions such as POAG and suspected glaucoma.

\section{MATERIALS AND METHODS}

Anonymised clinical data recorded between April 2000 and March 2015 were extracted from the Medisoft (Medisoft, Leeds, UK) EMR at five different NHS Hospital Trust glaucoma clinics in England. Commissioned to do so by the Healthcare Quality Improvement Partnership as part of the National Clinical Audit and Patient Outcomes Programme, the Royal College of Ophthalmologists collected this data as the National Ophthalmology Database Audit 


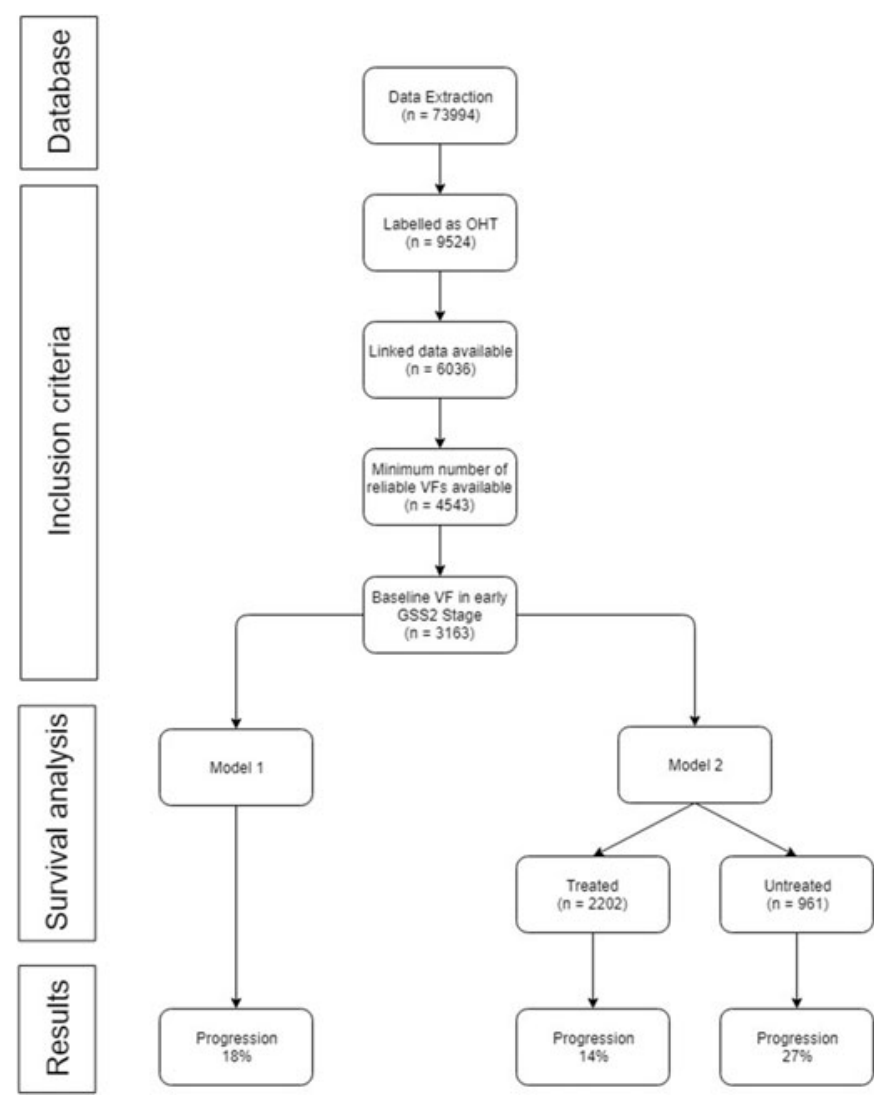

Figure 1 Flow chart of patient eye selection. The flow chart also shows the predicted proportion of conversion for model 1 (all-cause survival analysis) and model 2 (stratified by treatment group).

provider. ${ }^{14}{ }^{15}$ Details and summary statistics of these data are available elsewhere. ${ }^{16}$ The data extraction was done in November 2015. All patient data were anonymised and stored on a database securely held at the university.

\section{Inclusion criteria}

Figure 1 presents a flow chart for patient eye selection. With this EMR (Medisoft) every diagnosis entry is associated with a diagnosis code. As such, it is possible to search and filter for specific conditions by filtering for the associated code or codes. We included patients with a clinical diagnosis label of OHT in at least one eye with no prior glaucoma-related diagnoses for either eye and with no significant ocular comorbidities. Specifically, eyes with a visual acuity (VA) of 6/18 or worse, or a diagnosis label of cataract, corneal pathology or eye casualty attendance were excluded. Eyes with age-related macular degeneration were included if they had a VA better than 6/18. As we are considering the risk of VF loss at a patient level, we are concerned with VF loss to either eye. As such, if both eyes were eligible, the eye with the higher baseline IOP was chosen for this analysis as it is potentially at a higher risk of VF loss. If both eyes had the same baseline IOP, one eye was chosen at random. For the purpose of this study, only VFs tested by using the Humphrey Field Analyzer (Carl Zeiss Meditec, Dublin, California, USA) with the 24-2, white-on-white test strategy acquired with the Swedish Interactive Testing Algorithm (SITA Standard or SITA Fast) were included in the analysis. A minimum of three reliable VF tests were required; one at baseline and two consecutive reliable examinations to enable detection of repeated VF loss if present.
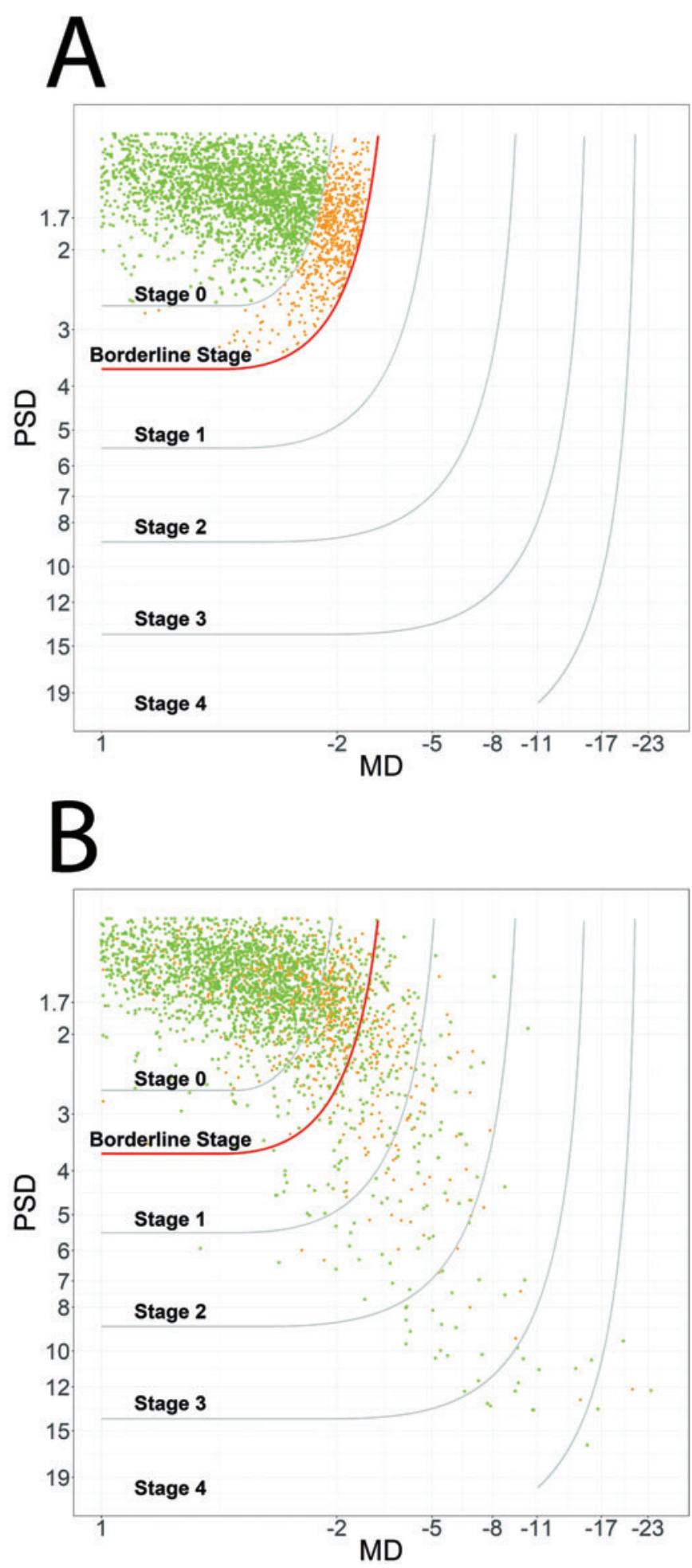

Figure 2 A glaucoma staging system 2 (GSS2) scatterplot showing the eyes included for analysis. Only eyes with a baseline measurement in the early stages (stage 0 (green) or borderline (orange) stage, demarked by a red curve) were included (A). A second scatterplot illustrating the GSS2 stage of the last recorded follow-up visit for the same eyes is also shown (B). OHT, ocular hypertension; $\mathrm{VF}$, visual field.

To classify patients into different levels of VF damage, we used the glaucoma staging system 2 (GSS2) described by Brusini and Filacorda. ${ }^{17}$ The system classifies VF damage into one of seven progressively worsening categories. As we wanted to consider 'true' OHT patients, we opted to only include eyes 

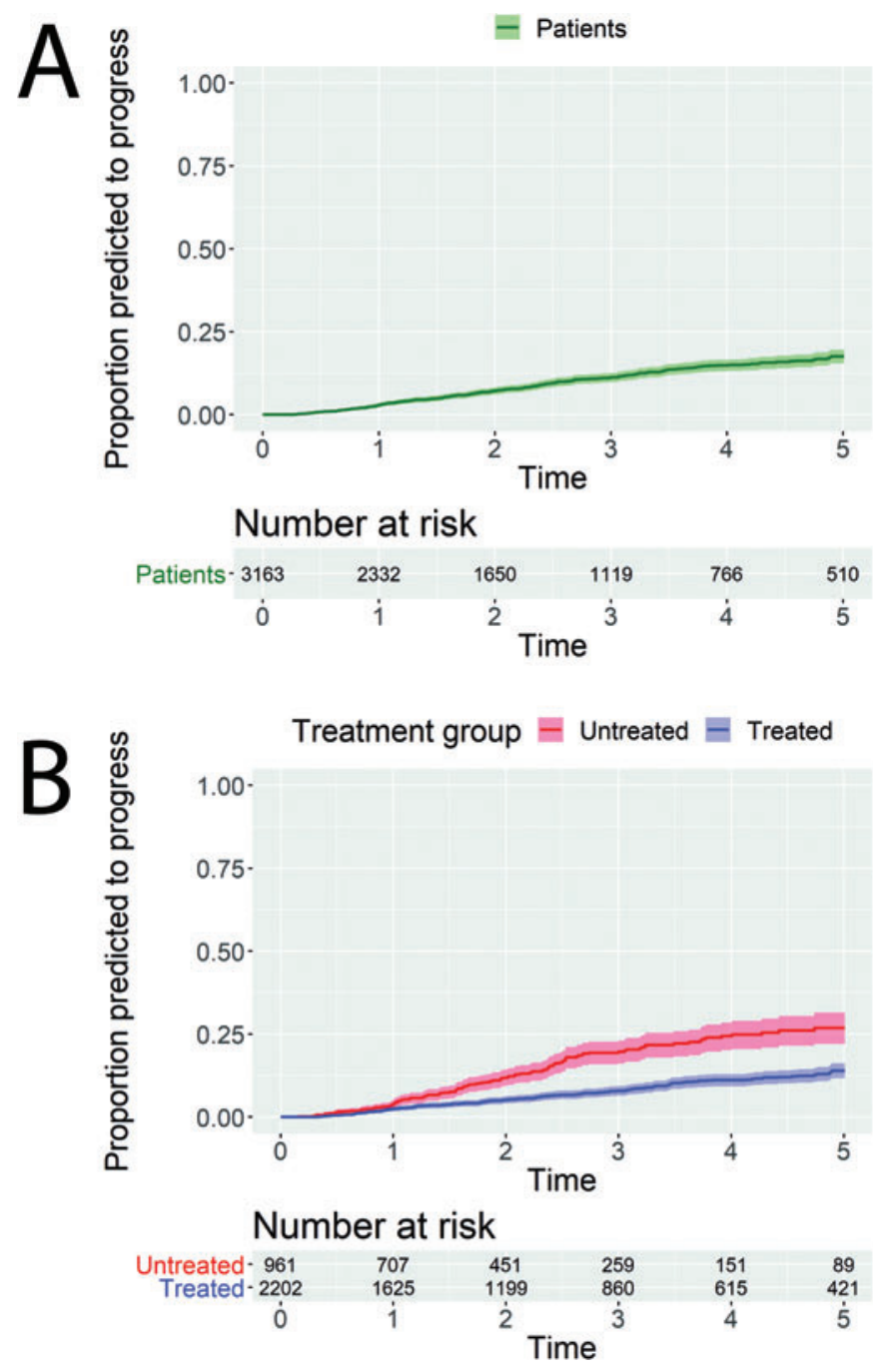

Figure 3 Cox PH survival curve of 5-year conversion predictions for (A) all patients (green) and (B) the treated (blue) and untreated (red) groups with the $95 \% \mathrm{Cls}$. The risk table shows the number of patients still included in the analysis for a group over time (1-year intervals). The cumulative probability of conversion was higher in the untreated group than the treated group $(p<0.01)$, (B). PH, proportional hazard.

with little-to-no VF damage at baseline, as defined by the GSS2 (stage 0 or borderline stage). Baseline VF was defined as the VF closest to the time of diagnosis labelling, with a maximum of 1 year between the diagnosis and VF test. Baseline stages as measured by the GSS2 for all included eyes can be seen in figure $2 \mathrm{~A}$. The GSS2 stage at the last recorded follow-up visit is also shown in figure $2 \mathrm{~B}$.

\section{Statistical analysis}

We considered follow-up VF data for up to 5 years following diagnosis of OHT. Any visits after this 5-year window were excluded. Two consecutive reliable VF exams with a GSS2 classification of stage 1 or worse were used to define VF loss. An unreliable VF was determined by the standard HFA criteria for false-positive errors $(>15 \%)$ or fixation-loss errors $(>20 \%)$. The VF with the earlier date was considered as the date of conversion. Patients with less than 5 years follow-up were included in the analysis but censored. The risk of conversion was calculated by computing the predicted survival function for a Cox proportional hazard $(\mathrm{PH})$ model. The

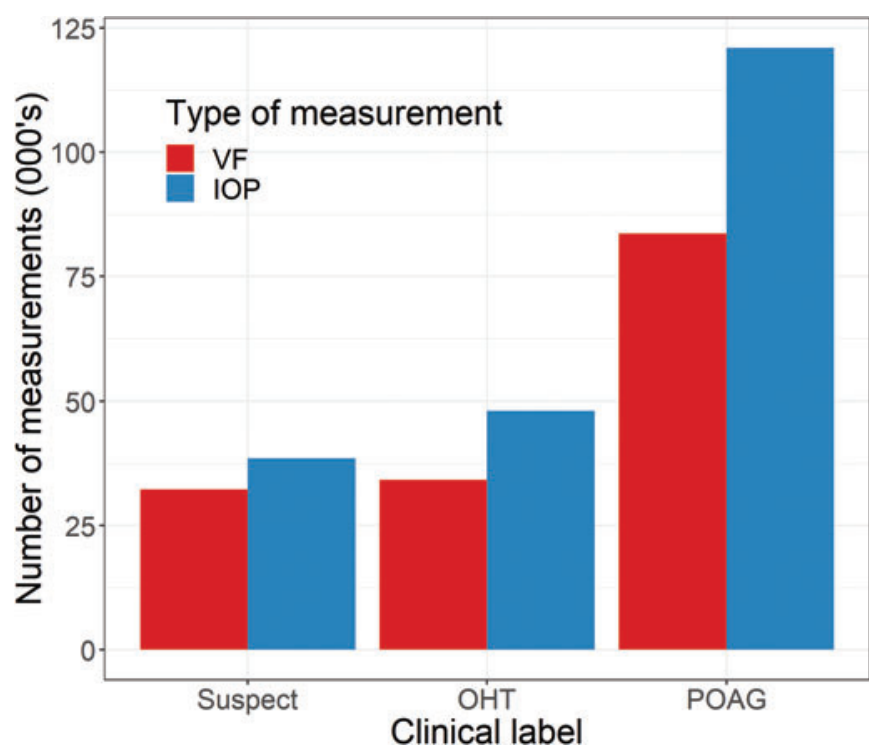

Figure 4 Number of recorded patient visits for IOP measurements (red) and VF testing (blue) by primary diagnosis (glaucoma suspect, OHT and POAG) across the full-time period in the dataset. IOP, intraocular pressure; $\mathrm{OHT}$, ocular hypertension; POAG, primary open-angle glaucoma; VF, visual field.

predicted survival functions were computed for a simple model (all-case conversion) and a model with IOP treatment as a predictor (figure 3 ).

Cox $\mathrm{PH}$ regression analysis was used to examine the baseline factors associated with incident conversion. Age, sex, baseline IOP (mm Hg) and treatment group (treated vs untreated) were examined both crudely and then together in a multivariable model. The treated group was defined as eyes that had a record of IOP-lowering medication, laser or surgery, while being labelled as an OHT patient (ie, before conversion in patients that developed POAG). The untreated group was defined as eyes that were recorded in the linked medications database but did not have any glaucoma medication listed and had no recorded glaucoma laser or surgery. To determine whether our results are affected by the choice of eye selected in patients with two eligible eyes, we repeated analyses for the fellow eye for bilaterally eligible patients instead of the originally included eye; results were very similar (online supplementary materials).

The relative burden of OHT, POAG and glaucoma suspect patients on the glaucoma clinics was estimated (figure 4). This was defined as the relative proportion of unique clinic visits (for IOP or VF measurements) for each of the three clinical diagnosis labels. A visit for one of the labels, say OHT, was defined as a visit date that occurred in the range of dates while the eye of interest was labelled as OHT. If the diagnosis label was updated at a later date, for example, from OHT to POAG, then subsequent visits would be counted as POAG visits. A visit where both eyes had the same label, would be counted as one visit for that label. A visit where both eyes had different labels, would be counted as a visit for the more 'serious' label (where POAG > glaucoma suspect $>$ OHT). The average number of months between VF tests for patients with at least four visits was calculated. All VF visits (including those with unreliable results) were included to better determine resource usage. All analyses were performed within the open-source statistical programming environment R. ${ }^{18} 19$ 


\begin{tabular}{|c|c|c|c|c|}
\hline $\begin{array}{l}\text { Included } \\
\text { (n) }\end{array}$ & $\begin{array}{l}\text { Median (IQR) } \\
\text { age at } \\
\text { diagnosis } \\
\text { (years) }\end{array}$ & $\begin{array}{l}\text { Median } \\
\text { (IQR) } \\
\text { baseline IOP } \\
(\mathrm{mm} \mathrm{Hg})\end{array}$ & $\begin{array}{l}\text { Median (IQR) } \\
\text { follow-up } \\
\text { IOP (mm Hg) }\end{array}$ & $\begin{array}{l}\text { Median (IQR) } \\
\text { Baseline visual } \\
\text { field mean } \\
\text { deviation (dB) }\end{array}$ \\
\hline 3163 & $60(51-66)$ & $24(20-27)$ & $\begin{array}{l}20.75 \\
(18.33-23.00)\end{array}$ & $-0.45(-1.32-0.34)$ \\
\hline
\end{tabular}

IOP, intraocular pressure.

\section{RESULTS}

\section{Baseline characteristics}

From the initial cohort of 9524 patients with a clinician diagnosis label of OHT, we included 3163 eyes from 3163 patients for our analysis (see figure 1 for inclusion flow chart). Of these, 1716 (54\%) were women, $2202(70 \%)$ were on IOP-lowering treatment during their OHT diagnosis and 1531 (48\%) were right eyes. For the included eyes, 4551/22 896 (20\%) of VF examinations were excluded due to unreliability. Other descriptive statistics can be found in table 1 .

\section{Cox PH analysis}

Survival analysis curves are shown in figure 3. Overall predicted conversion after 5 years was $17.5 \%$ (95\% CI $15.4 \%$ to $19.6 \%$ ) (figure $3 \mathrm{~A}$ ). When stratified by treated and untreated groups, the predicted conversion after 5 years was $14.0 \%(95 \%$ CI $11.7 \%$ to $16.1 \%)$ and $26.9 \%$ (95\% CI $22.0 \%$ to $31.4 \%)$, respectively (figure $3 \mathrm{~B}$ ). Of those that converted, $90 \%$ had mild or moderate VF loss (GSS stage 1 or Stage 2) and 10\% had severe (GSS stage 3 or Stage 4). Results of the Cox regressions (univariable and multivariable) are shown in table 2 . Use of IOPlowering treatment was associated with a reduced chance of conversion; HR 0.45 (95\% CI 0.35 to 0.57 , p <0.001). Older age was associated with an increased risk of conversion (HR 1.35 per decade, $95 \%$ CI 1.22 to $1.50, \mathrm{p}<0.001)$. There was no statistically significant association between risk of conversion and baseline IOP or sex.

\section{Burden on clinics}

Of the total number of unique visits (recording either a VF or IOP measurement or both) for the three clinical labels included for analysis, 21\% were recorded for glaucoma suspect patients, 22\% for OHT patients and 57\% for POAG patients. Considering only VF measurements, the distribution was 23\%, 23\% and 54\% for glaucoma suspects, OHT and POAG patients, respectively. For IOP measurements only, the distribution was 20\%, 23\% and 57\% (absolute numbers are shown in figure 4).

If we only consider the 3163 patients who were included in the survival analysis, 11727 of 15464 (76\%) of the visits within the 5 -year study window were recorded while the eye was receiving IOP-lowering treatment. This corresponds to $76 \%$ and $74 \%$ of

\begin{tabular}{lllll}
\hline $\begin{array}{l}\text { Table } 2 \\
\text { analyses }\end{array}$ & Results of COX PH survival univariable and multivariable \\
\hline Variable name & $\begin{array}{l}\text { HR with } 95 \% \mathrm{Cl} \\
\text { (univariable) }\end{array}$ & $\begin{array}{l}\text { P value } \\
\text { HR with } 95 \% \mathrm{Cl}\end{array}$ & $\begin{array}{l}\text { (multivariable) } \\
\text { P value }\end{array}$ \\
\hline Baseline age (decade) & $1.36(1.22$ to 1.51$)$ & $<0.001$ & $1.35(1.22$ to 1.50$)$ & $<0.001$ \\
\hline Baseline IOP (mm Hg) & $1.00(0.97$ to 1.02$)$ & 0.70 & $1.00(0.98$ to 1.03$)$ & 0.98 \\
\hline Sex (F) & $1.07(0.85$ to 1.35$)$ & 0.56 & $0.99(0.78$ to 1.25$)$ & 0.93 \\
\hline Treatment (yes) & $0.44(0.35$ to 0.56$)$ & $<0.001$ & $0.45(0.35$ to 0.56$)$ & $<0.001$ \\
\hline
\end{tabular}

IOP, intraocular pressure; $\mathrm{PH}$, proportional hazard. the IOP and VF measurements, respectively. For patients with at least four VF visits, the average time between VF tests was 10.9, 9.7 and 9.6 months for glaucoma suspects, OHT patients and POAG patients, respectively.

\section{DISCUSSION}

This is the first study to use large-scale, real-world EMR data from glaucoma clinics to model conversion from OHT to POAG. Our survival analysis predicts that around one in six $(17.5 \%)$ OHT patients will have detectable VF loss within 5 years and the majority of those $(67 \%)$ will have mild VF loss (GSS stage 1). In our study population, $70 \%$ of the OHT patients were receiving IOP-lowering treatment and these patients had a lower predicted rate of conversion of around one in eight (14\%). This indicates that there are many OHT patients in the clinics, especially those who are being treated, that are unlikely to lose much VF function within a 5-year window. Despite this, our data show that the average frequency of VF and IOP monitoring across OHT patients, POAG patients and glaucoma suspects is similar.

In a large multicentre clinical trial, the Ocular Hypertension Treatment Study (OHTS), the cumulative probability of developing POAG at 5 years was $4.4 \%$ in the treated group $9.5 \%$ and in the untreated group. ${ }^{20}$ In another study, the European Glaucoma Prevention Study (EGPS), the conversion rates were $13.7 \%$ and $16.4 \%$, respectively. ${ }^{4}$ Our treated and untreated rates of conversion (14\% and $26.9 \%)$ seem relatively high when compared with the above trials. There are several possible reasons for this discrepancy. First, we did not use any structure-based data (such as optic disc changes) for the inclusion or conversion criteria as was done in OHTS and EGPS, instead relying on the diagnostic labelling in the EMR. ${ }^{4}{ }^{20}$ Second, we may be overestimating the conversion rate if OHT patients with perceived low risk (eg, patients with thick corneas) were discharged to community review without treatment. Finally, it is possible that OHT patients being monitored in a hospital glaucoma clinic in England are a higher risk population than those in the studies described above, and so would have a higher likelihood of conversion to POAG.

Just over one in five (22\%), glaucoma-related visits (OHT, POAG or glaucoma suspect visits) were for OHT patients. If only $17.5 \%$ of patients are predicted to have detectable VF loss within 5 years, is it necessary that they be seen in secondary care clinics this frequently, considering that the risk of significant vision loss is very low (only $1.75 \%$ of our study population reaching severe VF loss)? There are several alternative options available that would reduce the burden on hospitals and glaucoma clinics, such as monitoring patients in primary care practices or in virtual clinics. So-called 'shared care' schemes could be a possible approach for low risk OHT patients. $^{8} 2122$ Notably, OHT patients had VF testing as frequently as both POAG and glaucoma suspect patients further emphasising that OHT patients are using a disproportionate amount of resources, relative to the immediate risk of VF loss. One suggestion to reduce the burden of OHT patients could be to increase the follow-up period between appointments. ${ }^{8}$ Morley and Murdoch estimated that increasing time between follow-up visits by a factor of 1.5 could reduce the relative clinic workload by $30 \%$. If the follow-up time was increased by a similar factor for stable, low-risk OHT patients, it could free up resources for high-risk or new patients. 
A caveat of using this retrospective observational data is we cannot say for sure that the treatment caused a lower rate of conversion, as there may have been differential allocation of treatment by risk of conversion. However, it seems unlikely that eyes at lower risk of conversion would preferentially be given treatment. Another limitation of our approach is that we did not have data regarding other potential risk factors for conversion, such as family history, central corneal thickness or retinal nerve fibre defects. The OHTS reported an HR of 0.58 (95\% CI 0.44 to 0.76 ) of IOP medication on conversion to POAG in the context of a randomised controlled trial. Our study illustrates the efficacy of treatment outside the context of a clinical trial. Age was also a significant predictor of conversion, both in our study and in the OHTS with our results being broadly in agreement with the OHTS HR of 1.22 (95\% CI 1.01 to 1.49$)$ per decade. $^{3}$ When designing the study protocol, one option was to consider a change of diagnosis label as an outcome for conversion. However, instead we opted for an objective measure using VF results that did not rely on a clinician updating the diagnosis label in the EMR. We rely on initial diagnostic labels, along with VF status to define our population when establishing baseline status, but not for detection of conversion. For added robustness, we also required a reliable baseline VF measurement indicating no VF damage, as classified by the GSS2. As the dataset did not include any objective structural data, this study did not examine OHT patients progressing to POAG in a strict clinical sense, but rather investigated the likelihood of developing VF loss in OHT patients. For the analysis on clinic burden, we faithfully reported visits as they appeared in the EMR and did not try to refine the labels based on, say, VF measurements. This is a minor limitation as it is possible that labels are not always updated as conscientiously they should be after status conversion.

The diagnosis labels and dates of diagnosis we used in this study to select OHT patients are to be interpreted as surrogates of disease presentation. For this analysis, we used the first recorded VF date as a surrogate of when the disease began. However, it is sometimes the case that patients come into a clinic previously diagnosed with OHT and already are being treated for some time before being entered into the EMR. Retrospective analyses such as ours are only possible if the data are accurately recorded in EMRs in a structured way. Today, many medical record systems are being digitised which makes the possibility of large, multicentre studies using 'big-data' much more feasible. ${ }^{12}$ As these data are already being recorded routinely, there is an opportunity of relatively cheap and accessible healthcare research, and patient benefit, to be gained from exploring them. Moreover, as these data come straight from clinics, it can tell us more about what goes on in real-world scenarios, which could inform how we organise our healthcare systems.

According to the National Institute for Health and Care Excellence glaucoma guidelines, 1.3 million people over aged 40 in the UK have high eye pressure (above $24 \mathrm{~mm}$ $\mathrm{Hg}$ ) and most of those who have this condition are monitored in HESs. ${ }^{1}$ Less than one-fifth of OHT patients managed in the reported UK glaucoma clinics converted to POAG over a 5 -year period. The majority of those conversions were to a mild disease stage. Simultaneously it is equally important to highlight results from those patients that were in clinics but were untreated. That is, more than $25 \%$ of the untreated OHT patients converted to POAG, although to a relatively mild disease stage within the time of follow-up. While it is difficult to extrapolate these findings to life-time risk of visual loss, since even mild disease can have an impact on quality of life, it is likely that these patients will be at an increased risk of sight-related harm during their lives. The results from this study highlight the issue of a 'one size fits all' approach in glaucoma clinics around the UK. Despite many of the referrals to secondary care being deemed as low risk, there is often a reluctance to discharge to community review. ${ }^{8}$ Moreover, there are several potential barriers to discharging patients to primary care pertaining to agreement on professional boundaries and responsibilities. $^{23}$ Nevertheless, many people with OHT and without VF loss, are at a low risk of sight loss in the near future. Yet, according to our data, they take up a relatively large proportion of resources and are seen as frequently as POAG patients. Our results suggest that it would be reasonable to reduce the frequency of visits for OHT patients and perhaps this should be explored with prospective study incorporating a health economic and patient preference element too, echoing a need for further work that has been reported before. ${ }^{24}$ It would furthermore be reasonable for such patients, who are not at risk of imminent sight loss, to be monitored by suitably trained and equipped optometric primary care practitioners, thus reducing the burden on hospital secondary eye care services.

\section{Twitter David PCrabb @crabblab}

Contributors SRK contributed to the design and implementation of the research, to the statistical analysis of the results and to the writing of the manuscript. APK contributed to the design and implementation of the research and to the writing of the manuscript. SRB contributed to the design and implementation of the research and to the writing of the manuscript. AA-B contributed to the design and implementation of the research and to the writing of the manuscript. JMS contributed to the design and implementation of the research and to the writing of the manuscript. DPC contributed to the design and implementation of the research, to the writing of the manuscript. and supervised the project. All authors discussed the results and contributed to the final manuscript.

Funding SRK received funding from the European Union's Horizon 2020 research and innovation program under the Marie Sklodowska-Curie grant agreement no. 675033. APK is supported by a Moorfields Eye Charity Career Development Fellowship. JMS is clinical lead for the HQIP commissioned National Ophthalmology Audit.

Disclaimer The listed funding organisations had no role in the design or conduct of this research.

Competing interests None declared.

Patient consent for publication Not required.

Ethics approval The current study was undertaken through a data-sharing agreement and adhered to the Declaration of Helsinki with all analyses approved by a research ethics committee of City, University of London.

Provenance and peer review Not commissioned; externally peer reviewed.

Data availability statement No data are available.

Open access This is an open access article distributed in accordance with the Creative Commons Attribution Non Commercial (CC BY-NC 4.0) license, which permits others to distribute, remix, adapt, build upon this work non-commercially, and license their derivative works on different terms, provided the original work is properly cited, appropriate credit is given, any changes made indicated, and the use is noncommercial. See: http://creativecommons.org/licenses/by-nc/4.0/.

\section{ORCID iDs}

Stephen R Kelly http://orcid.org/0000-0002-4334-9355

Anthony P Khawaja http://orcid.org/0000-0001-6802-8585

Susan R Bryan https://orcid.org/0000-0002-8327-0668

Augusto Azuara-Blanco http://orcid.org/0000-0002-4805-9322

John M Sparrow http://orcid.org/000-0003-3704-0105

David P Crabb https://orcid.org/0000-0001-8754-3902 


\section{REFERENCES}

1 National Institute for Health and Care Excellence (NICE). Glaucoma: diagnosis and management, 2017. Available: https://www.nice.org.uk/guidance/ng81/resources/gla ucoma-diagnosis-and-management-pdf-1837689655237

2 Chan MPY, Broadway DC, Khawaja AP, et al. Glaucoma and intraocular pressure in EPIC-Norfolk eye study: cross sectional study. BMJ 2017;358:j3889.

3 Gordon MO, Beiser JA, Brandt JD, et al. The ocular hypertension treatment study: baseline factors that predict the onset of primary open-angle glaucoma. Arch Ophthalmol 2002;120:714-20.

4 Miglior S, Zeyen T, Pfeiffer N, et al. Results of the European glaucoma prevention study. Ophthalmology 2005;112:366-75.

5 Medeiros FA. Validation of a predictive model to estimate the risk of conversion from ocular hypertension to glaucoma. Arch Ophthal 2005;123:1351.

6 Salvetat ML, Zeppieri M, Tosoni C, et al. Baseline factors predicting the risk of conversion from ocular hypertension to primary open-angle glaucoma during a 10-year follow-up. Eye 2016;30:784-95.

7 Prokofyeva E, Zrenner E. Epidemiology of major eye diseases leading to blindness in Europe: a literature review. Ophthalmic Res 2012;47:171-88.

8 Morley AMS, Murdoch I. The future of glaucoma clinics. Br J Ophthalmol 2006;90:640-5.

9 Chalk D, Smith M. Guidelines on glaucoma and the demand for services. Br J Healthc Manag 2013;19:476-81.

10 Tatham A, Murdoch I. The effect of appointment rescheduling on monitoring interval and patient attendance in the glaucoma outpatient clinic. Eye 2012;26:729-33.

11 Broadway DC, Tibbenham K. Tackling the NHS glaucoma clinic backlog issue. Eye 2019;33:1715-21.

12 Wachter RM. Making IT work: harnessing the power of health IT to improve care in England, 2016. Available: https://www.gov.uk/government/uploads/system/uploads/ attachment_data/file/550866/Wachter_Review_Accessible.pdf\%0Ahttps://assets publishing.service.gov.uk/government/uploads/system/uploads/attachment_data/file/ 550866/Wachter_Review_Accessible.pdf
13 Honeyman M, Dunn D, McKenna H. A digital NHS? an introduction to the digital agenda and plans for implementation, 2016. Available: http://www.kingsfund.org.uk /publications/digital-nhs

14 Day AC, Donachie PHJ, Sparrow JM, et al. The Royal College of Ophthalmologists National Ophthalmology Database study of cataract surgery: report 1, visual outcomes and complications. Eye 2015;29:552-60.

15 Jackson TL, Donachie PHJ, Sparrow JM, et al. United Kingdom national ophthalmology database study of vitreoretinal surgery: report 1; case mix, complications, and cataract. Eye 2013;27:644-51.

16 The RCOphth NOD Audit Team. National electronic glaucoma surgery and visual field preservation audit: feasibility report, 2017. Available: https://www.nodaudit.org.uk/u/ docs/20/joxmqddqpu/Glaucoma Surgery and Visual Fields Audit Feasibility Report.pdf [Accessed 18 Jul 2019].

17 Brusini P, Filacorda S. Enhanced glaucoma staging system (GSS 2) for classifying functional damage in glaucoma. J Glaucoma 2006;15:40-6.

18 Heijl A, Lindgren G, Olsson J. A package for the statistical analysis of visual fields. In: Greve EL, Heiil A, eds. Seventh International visual field symposium, Amsterdam, September 1986. Springer Netherlands: Dordrecht, 1987: 153-68.

19 R Core Team. R core team. R: a language and environment for statistical computing $\mathrm{R}$ foundation for statistical computing, Vienna, Austria,. Available: http://www.R-proj ect.org/

20 Kass MA. The ocular hypertension treatment study. Arch Ophthal 2002;120:701-13.

21 Gray SF, Spry PG, Brookes ST, et al. The Bristol shared care glaucoma study: outcome at follow up at 2 years. Br J Ophthalmol 2000;84:456-63.

22 Vernon SA, Adair A. Shared care in glaucoma: a national study of secondary care lead schemes in England. Eye 2010;24:265-9.

23 Holtzer-Goor KM, Plochg T, Lemij HG, et al. Why a successful task substitution in glaucoma care could not be transferred from a hospital setting to a primary care setting: a qualitative study. Implement Sci 2013;8:1-10.

24 Hernández R, Burr JM, Vale L, et al. Monitoring ocular hypertension, how much and how often? A cost-effectiveness perspective. Br J Ophthalmol 2016;100:1263-8. 